\section{Radiation Induced Demyelination in Cervical Spinal Cord of the Head and Neck Cancer Patients after Receiving Radiotherapy}

\author{
Goyal H. ${ }^{\oplus}$, Singh N. ${ }^{2 *} \oplus$, Gurjar O. P. ${ }^{3}$, Tanwar R. K. ${ }^{1}$
}

\begin{abstract}
Background: Cervical spinal cord is important and radiosensitive. It is the most critical organ for the head and neck $(\mathrm{H} \& \mathrm{~N})$ cancer patients during radiotherapy. If the delivered dose to the cord is more than tolerance dose, demyelination may occur.

Objective: Current study aims to analyze the post radiotherapy status of cord in the $H \& N$ cancer patients.

Material and Methods: In this analytical study, sixty patients who received more than 50 Gray (Gy) dose for more than $10 \mathrm{~cm}$ length of spinal cord participated in the study. All the patients were clinically examined and magnetic resonance imaging (MRI) was performed for patients who had demyelination symptoms. Adequate medical management was provided for all the patients having demyelination.

Results: Out of sixty patients, ten cases were reported with demyelination symptoms, and only six cases gave consent for this study. One patient was found to have irreversible demyelination while five patients had reversible demyelination.
\end{abstract}

Conclusion: Demyelination may occur if long segment spinal cord receives dose more than tolerance limit. However target dose should not be compromised up to 54 Gy to spinal cord.

Citation: Goyal H, Singh N, Gurjar O. P, Tanwar R. K. Radiation Induced Demyelination in Cervical Spinal Cord of the Head and Neck Cancer Patients after Receiving Radiotherapy. J Biomed Phys Eng. 2020;10(1):1-6. doi: 10.31661/jbpe.v0i0.1055.

\section{Keywords}

Spinal Cord; Demyelination; Myelin; Radiotherapy; Magnetic Resonance Imaging

\section{Introduction}

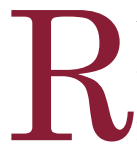

udolf Virchow discovered Myelin in 1854 [1]. For proper functioning of the nervous system, myelin is a very crucial component. Myelin is a lipid-rich substance wrapping around nerve fibers and leading to increase the speed of electrical communication between neurons. Formation of myelin sheath is known as myelinogenesis or myelination. Loss of myelin sheath or degeneration of myelin is known as demyelination [2]. In the central nervous system (CNS), myelin is made from two different types of support cells. In brain and spinal cord cells, it is called oligodendrocyte, which wraps their branch-like extensions around axons to create a myelin sheath. In the nerves outside of the spinal cord, Schwann cells produce myelin. Regardless of where it is in the nervous system, myelin performs the same function enabling

${ }^{1} \mathrm{MD}$, Department of Radiotherapy, Government Medical College \& Hospital, Kota, India

${ }^{2} \mathrm{PhD}$, Department of Radiotherapy, King George Medical University,

Lucknow, India

${ }^{3} \mathrm{PhD}$, Government Can-

cer Hospital, Mahatma

Gandhi Memorial Medi-

cal College, Indore, India

. 
efficient transmission of electrical signals.

A demyelinating disease is a kind of nervous system diseases in which the myelin sheath of neurons is damaged [2]. This demyelination disease causes deficiency in sensation, conduction ability, movement, cognition, or other functions depending on which nerves are involved. Etiology of demyelination basically consists of autoimmune, inflammatory, genetics, radiation induced and chemical induced [3].

Owing to radiotherapy in cancer patients, symptoms of demyelination consist of blurred double vision, impaired vision, ataxia, unsteady gait, fatigue, numbness, incoordination, hemiparesis, paresthesias, ocular paralysis, impaired muscle coordination, weakness in muscle, loss of sensation, incontinence, hearing problems, speech problems, electrical sensation in limbs known as Lhermitte's sign [4].

As compared to other normal organs or neoplastic tissue, spinal cord is a critical organ showing enhanced radiosensivity. Misalignment or any calculation errors in radiotherapy planning or wrong setup in irradiation sessions may cause radiation induced myelopathy. Radiation induced demyelination may be irreversible or reversible depending upon dose of radiation, length, circumference and region of the spinal cord. Cervical region is the commonest part of the cord which is affected [5]. Symptoms appear after a latent period from six months to two years [6].

White and gray matter can be affected separately or in combination by complications of radiotherapy. Radiation-induced white matter injury (demyelination) are vegetative deficits, sensory, and spastic motor sequelae. If radiation involves motor sequelae which leads to rare recovery, radiation induced myelopathy will be followed as a reversible or irreversible, chronic, progressive course [7-10].

This study was carried out to analyze the patients of positive clinical neurological symptoms after receiving radiotherapy in head and neck (H\&N) cancer.

\section{Material and Methods}

In this analytical study, 321 patients with $\mathrm{H} \& \mathrm{~N}$ cancer received radiotherapy from January, 2015 to December, 2016. After a careful review, it was seen that only sixty patients who received 66 Gy in 33 fractions with three dimensional radiotherapy (3DCRT) planned with 6 megavoltage (MV) beam energy on linear accelerator were alive. The dose to spinal cord in all these sixty patients was above 50 Gy. Because of disease status, positive posterior neck nodes or gross disease were found suitable for this study. The mean maximum dose to spinal cord of these sixty patients was 53.8 Gy and the mean spine length receiving dose above 50 Gy was $12.16 \mathrm{~cm}$. All the patients got follow-up calls from six months to two years after completion of radiotherapy.

Neurological examination was taken for all the patients and those who were found positive with demyelination signs and symptoms (all six patients presented with Lhermitte's sign) were taken for magnetic resonance imaging (MRI) of spine by using Siemens Magnetom Symphony 1.5T MRI System (Siemens Medical Systems, Germany). Based on MRI report, pregabalin and vitamin B12 were prescribed to all the patients who were found positive with demyelination.

\section{Results}

Sixty patients were found suitable for the study, out of which only 10 patients were presented with demyelination signs and symptoms. Only six patients gave consent for this study, therefore all these six patients were undergone through complete clinical neurological examination and MRI scan. Figure 1 shows the MRI images of one patient with cervical spine suggestive of demyelination. Out of six patients, one patient was presented with irreversible demyelination and 5 patients were presented with reversible demyelination. Figure 2 shows the planning images for one of 


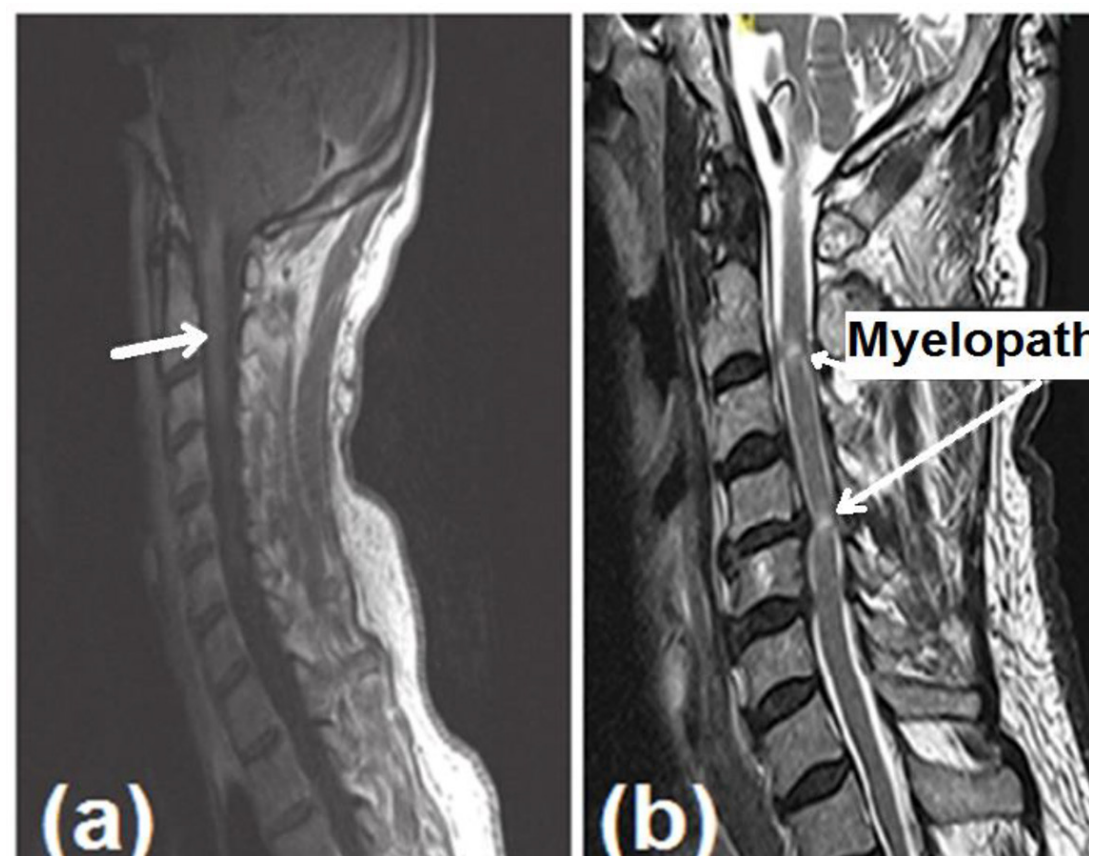

Figure 1: MRI images of (a) lesion appears isointense on T1 W1 (b) cervical spine T2 weighted images reveals small intramedullary area of T2 prolongation in the cervical cord at C2-C3 level, without any obvious cord swelling or mass effect and in a given clinical setting represent demyelination.
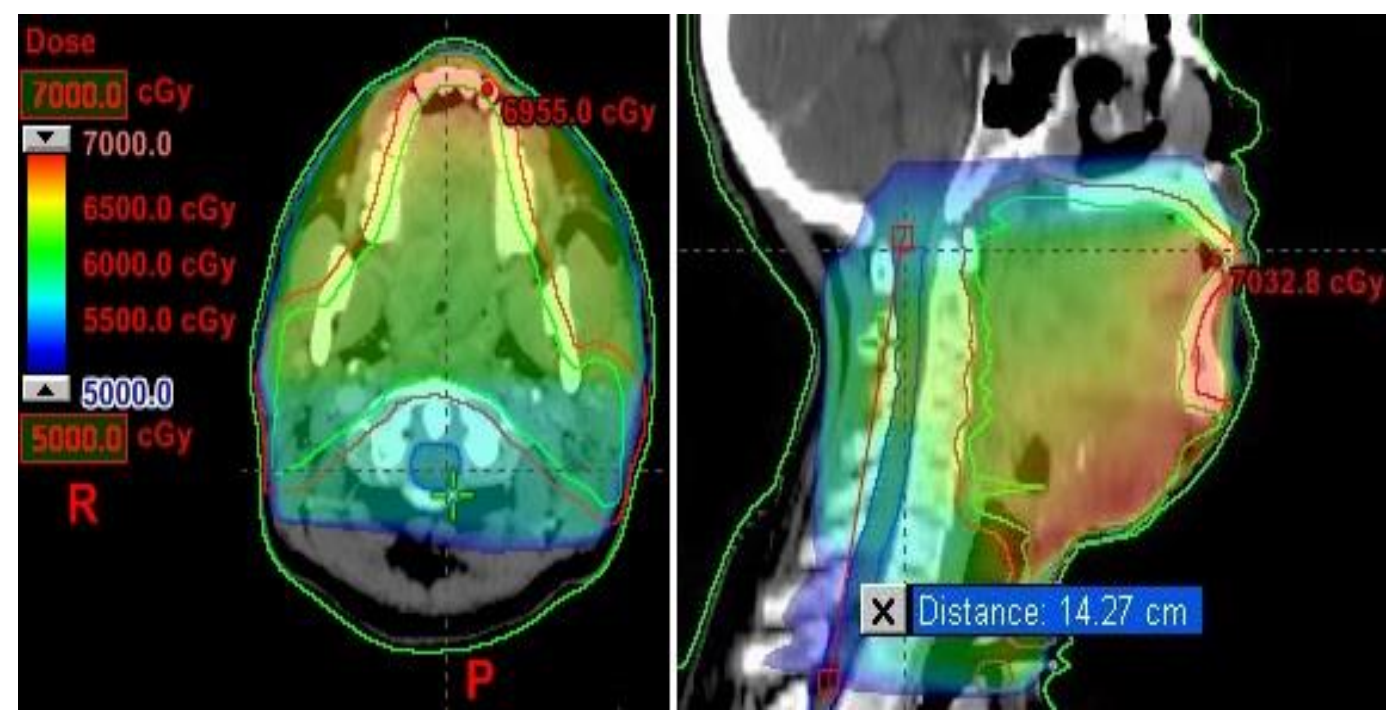

Figure 2: Cross-sectional and sagittal view for one of the patient's plan showing $50 \mathrm{~Gy}$ to the spinal cord with involvement of spinal length $14.27 \mathrm{~cm}$. 
the patients with 50 Gy dose color wash and length of cervical spine covered with $50 \mathrm{~Gy}$. Table 1 represents the number of patients with maximum dose to spinal cord, length of the spinal cord received more than 50 Gy and reversible/irreversible demyelination.

\section{Discussion}

Radiation induced demyelination is an uncommon serious adverse effect of radiotherapy that usually develops six months to two years after radiotherapy [6]. The pathophysiology of radiation induced demyelination is incom-

Table 1: Number of patients with maximum dose to spinal cord and the length of spinal cord received more than $50 \mathrm{~Gy}$.

\begin{tabular}{ccccccc}
$\begin{array}{c}\text { No. of } \\
\text { patients }\end{array}$ & $\begin{array}{c}\text { Max dose } \\
\text { received by } \\
\text { spinal cord } \\
\text { (Gy) }\end{array}$ & $\begin{array}{c}\text { Total dose de- } \\
\text { livered Gy/ no. } \\
\text { of fractions }\end{array}$ & $\begin{array}{c}\text { Mean length of } \\
\text { cord received } \\
\mathbf{2} \mathbf{5 0} \mathbf{~ G y ~} \mathbf{( c m )}\end{array}$ & $\begin{array}{c}\text { Patients having } \\
\text { demyelination } \\
\text { symptoms }\end{array}$ & $\begin{array}{c}\text { Included in } \\
\text { the study }\end{array}$ & $\begin{array}{c}\text { Reversible/ } \\
\text { irreversible }\end{array}$ \\
\hline 25 & $50-51$ & $66 / 33$ & 11.88 & 0 & 0 & \\
\hline 24 & $52-53$ & $66 / 33$ & 12.1 & 0 & 0 & \\
\hline 2 & $54-55$ & $66 / 33$ & 14.13 & 2 & 1 & reversible \\
\hline 9 & $56-57$ & $66 / 33$ & 12.67 & 8 & 5 & 1 irreversible, \\
4 & & & & & & \\
\hline
\end{tabular}

pletely understood; however, it is believed that it is a slowly evolving process involving vascular endothelial damage, fibrinoid necrosis and microscopic coagulation [11].

The cervical portion of the spinal cord is more radiosensitive than other parts of spinal cord when a high dose of radiation was received by the cervical spinal cord and then it causes loss of myelin and axons within the lateral (mainly) and posterior columns. The radiation tolerance of the spinal cord is dependent on a number of factors, including total dose, dose per fraction, total time, volume, host factors, radiation quality (linear energy transfer) and adjunctive therapies as shown in Table 2 $[12,13]$.

Age, hypertension, diabetes mellitus, vascular disease, developmental abnormalities and endocrinological disease are the important factors playing a role in formation of myelin [14].

Diagnostic work-up usually shows nonspecific results. MRI scan with gadolinium scan is the most acceptable method to detect demy-
Table 2: Factors which enhances the risk of demyelination.

\begin{tabular}{cc} 
Factors & $\begin{array}{c}\text { Factors for increased risk of } \\
\text { injury }\end{array}$ \\
\hline Total dose & Higher total dose \\
\hline $\begin{array}{c}\text { Dose per } \\
\text { fraction }\end{array}$ & Dose per fraction $>200$ cGy \\
\hline Volume & Increased volume, e.g. whole-organ radiation \\
\hline Host factors & Medical illness, e.g. hypertension, diabetes \\
\hline Beam quality & High LET radiation beams, e.g. neutrons
\end{tabular}

elination. MRI may show cord demyelination finding, or cord swelling decreasing intensity in T1 and increasing it in T2 images, which are indicative of edema. The prognosis depends primarily upon the degree and level where the cord is irradiated [15].

Conservative and supportive approach is the treatment of demyelination where vitamin D3 (cholecalciferil) has a vital role in recovery of demyelination; people suffering from myelin sheath degeneration are observed with high vitamin D deficiency. Vitamin B12 is a very es- 
sential component for function and formation of myelin sheath; it provides myelin sheath strengthening. Patients with demyelination were present with deficiencies of vitamin B12 in blood and cerebrospinal fluid. Deficiencies of vitamin B12 not only enhance myelin destruction but also it alters myelin repair [16].

Role of Lecithin also established factors in demyelination, and it helps to build blocks for neuronal membrane. One of the important brain chemicals is known as glutathione which acts as antioxidant. It helps to preserve nerve tissue injury by free radicals. Non-denatured whey protein powder also helps to raise intracellular glutathione level [16].

\section{Conclusion}

Demyelination may occur if the dose to spinal cord exceeds $54 \mathrm{~Gy}$. The ratio of irreversible demyelination was only $1.6 \%$ while reversible demyelination was $8.3 \%$. It can be concluded that target dose should not be compromised up to 54 Gy to spinal cord.

\section{Conflict of Interest}

None

\section{References}

1. Boullerne Al. The history of myelin. Exp Neurol. 2016;283:431-45.

2. Weil MT, Mobius W, Winkler A, Ruhwedel T, Wrzos C, Romanelli E, et al. Loss of Myelin Basic Protein Function Triggers Myelin Breakdown in Models of Demyelinating Diseases. Cell Rep. 2016;16:314-22. doi: 10.1016/j.celrep.2016.06.008. PubMed PMID: 27346352. PubMed PMCID: PMC4949381.

3. Konopaske GT, Dorph-Petersen KA, Sweet RA, Pierri JN, Zhang W, Sampson AR, et al. Effect of chronic antipsychotic exposure on astrocyte and oligodendrocyte numbers in macaque monkeys. Biol Psychiatry. 2008;63:759-65. doi: 10.1016/j. biopsych.2007.08.018. PubMed PMID: 17945195. PubMed PMCID: PMC2386415.

4. Love S. Demyelinating diseases. J Clin Pathol. 2006;59:1151-9. doi: 10.1136/jcp.2005.031195. PubMed PMID: 17071802. PubMed PMCID: PMC1860500.
5. Okada S, Okeda R. Pathology of radiation myelopathy. Neuropathology. 2001;21:247-65. doi: 10.1046/j.1440-1789.2001.00408.x. PubMed PMID: 11837531.

6. Ahlbom HE. The results of radiotherapy of hypopharyngeal cancer at the Radiumhemmet, Stockholm, 1930 to 1939. Acta Radiol. 1941;22:15571. doi: 10.3109/00016924109171582.

7. Jellinger K, Sturm KW. Delayed radiation myelopathy in man. Report of twelve necropsy cases. J Neurol Sci. 1971;14:389-408. PubMed PMID: 5125754. doi: 10.1016/0022-510x(71)90174-2.

8. Kristensson K, Molin B, Sourander P. Delayed radiation lesions of the human spinal cord. Report of five cases. Acta Neuropathol. 1967;9:3444. doi: 10.1007/bf00688156. PubMed PMID: 6049792.

9. Palmer JJ. Radiation myelopathy. Brain. 1972;95:109-22. doi: 10.1093/brain/95.1.109. PubMed PMID: 5023080.

10. Reagan TJ, Thomas JE, Colby MY. Chronic progressive radiation myelopathy. Its clinical aspects and differential diagnosis. JAMA. 1968;203:10610. doi: 10.1001/jama.1968.03140020034009. PubMed PMID: 5694057.

11. Burger PC, Mahley Jr MS, Dudka L, Vogel FS. The morphologic effects of radiation administered therapeutically for intracranial gliomas: a postmortem study of 25 cases. Cancer. 1979;44:1256-72. doi: 10.1002/1097-0142(197910)44:4<1256::aidcncr2820440415>3.0.co;2-t. PubMed PMID: 387205.

12. Leibel S, Sheline G. Tolerance of the brain and spinal cord to conventional irradiation. United States: Radiation injury to the nervous system; 1991. p. 211-238.

13. Schultheiss TE, Kun LE, Ang KK, Stephens LC. Radiation response of the central nervous system. Int J Radiat Oncol Biol Phys. 1995;31:1093112. doi: 10.1016/0360-3016(94)00655-5. PubMed PMID: 7677836.

14. Lengyel Z, Reko G, Majtenyi K, Pisch J, Csornai $M$, Lesznyak J, et al. Autopsy verifies demyelination and lack of vascular damage in partially reversible radiation myelopathy. Spinal Cord. 2003;41:577-85. doi: 10.1038/sj.sc.3101480. PubMed PMID: 14504618.

15. Tillema JM, Pirko I. Neuroradiological evaluation of demyelinating disease. Ther Adv Neurol Disord. 2013;6:249-68. doi: 
Goyal H. et al

10.1177/1756285613478870. PubMed PMID: 23858328. PubMed PMCID: PMC3707351.

16. Symptoms of Multiple Sclerosis and Myelin
Sheath Degeneration [Internet]. c2004-2017. [Accessed 28 October 2017]. Available from: https://evenbetterhealth.com. 